\title{
Comparison of Pain Tolerance between Opioid Dependent Patients on Methadone Maintenance Therapy (MMT) and Opioid Naive Individuals
}

Zalina Zahari ${ }^{1,2}$, Chee Siong Lee ${ }^{3}$, Muslih Abdulkarim Ibrahim ${ }^{2,4}$, Nurfadhlina Musa ${ }^{2}$, Mohd Azhar Mohd Yasin ${ }^{2,5}$, Yeong Yeh Lee ${ }^{6}$, Soo Choon Tan ${ }^{2}$, Nasir Mohamad ${ }^{2,7}$ and Rusli Ismail ${ }^{2,8}$

${ }^{1}$ Department of Pharmacy, Hospital Universiti Sains Malaysia, Kelantan, Malaysia. ${ }^{2}$ Pharmacogenetics and Novel Therapeutics Cluster, Institute for Research in Molecular Medicine (INFORMM), Universiti Sains Malaysia (USM), Kelantan, Malaysia. ${ }^{3}$ Department of Emergency Medicine, School of Medical Sciences, USM, Kelantan, Malaysia. ${ }^{4}$ Department of Pharmacology and Toxicology, College of Pharmacy, Hawler Medical University, Hawler, Iraq. ${ }^{5}$ Department of Psychiatry, School of Medical Sciences, USM, Kelantan, Malaysia. ${ }^{6}$ School of Medical Sciences, USM, Kelantan, Malaysia. ${ }^{7}$ Faculty of Medicine \& Health Sciences, Universiti Sultan Zainal Abidin, Terengganu, Malaysia. ${ }^{8}$ Centre of Excellence for Research in AIDS (CERiA), University of Malaya, Kuala Lumpur, Malaysia.

Received, November 10, 2015; Revised, February 9, 2016, Accepted, February 11, 2016. Published, February 11, 2016.

\begin{abstract}
Purpose: This study compared pain sensitivity among opioid dependent patients on methadone maintenance therapy (MMT) and opioid naive subjects. Methods: The three hundred participants comprised 152 opioid naive subjects and 148 opioid dependent patients. Opioid naive subjects had not taken any opioids including morphine and methadone to their best knowledge and were presumed so after two consecutive negative urine screenings for drugs. All opioid dependent patients were stabilized in treatment, defined as having been enrolled in the program for more than one month with no change of methadone dosage over the past one month. Excluded from the study were individuals with chronic or ongoing acute pain and individuals with a history of analgesics ingestion within $3 \mathrm{~d}$ before the cold pressor test (CPT). Pain tolerance to CPT was evaluated at $0 \mathrm{~h}$, and at 2, 4, 8, 12, and $24 \mathrm{~h}$ post-methadone dose. Results: Patients exhibited a significantly shorter mean pain tolerance time of $34.17 \mathrm{~s}(95 \%$ CI $24.86,43.49)$ versus $61.36(52.23,70.48)[p<0.001]$ compared with opioid naive subjects. Time-dependent mean pain tolerance was also significantly different when naive subjects were compared to patients $(p=0.016)$. Conclusions: This study revealed hyperalgesia amongst patients on MMT, as manifested by their quicker hand withdrawal. The complaints of pain in this population should not be underestimated and the pain should be evaluated seriously and managed aggressively.
\end{abstract}

This article is open to POST-PUBLICATION REVIEW. Registered readers (see "For Readers") may comment by clicking on ABSTRACT on the issue's contents page.

\section{INTRODUCTION}

Maintenance pharmacological treatments for opioid dependence are effective in retaining patients in treatment and suppressing drug use (1). More patients with opioid dependence are receiving methadone maintenance therapy (MMT) worldwide. However, data among 227 opioid dependent patients on MMT in Baltimore suggested that a significant number $(137,60 \%)$ of this patient population had chronic pain (2). In Malaysia, the starting age for drug use was between 14 to $35 \mathrm{y}$ and the mean age to enrolment in MMT was $42 \mathrm{y}$ (3). As a result, clinicians will more frequently encounter patients on MMT for management of pain due to trauma, acute medical illness and chronic diseases, and surgery (4). However, clinicians often underestimate the pain complaints in this patient population $(4,5)$.

Patients on MMT often receive under-treatment for acute and chronic pain $(5,6)$. Reasons for this include a lack of awareness among physician about treatment of chronic and acute pain in this patient population (6). Methadone maintained patients receive inadequate doses of opioid analgesics for their pain $(4,5,7,8)$. The stigma associated with MMT and opioid addiction among healthcare professionals causes them to have different approaches to treating patients with a

Corresponding Author: Zalina Zahari, Department of Pharmacy, Hospital Universiti Sains Malaysia, 16150 Kubang Kerian, Kelantan, Malaysia; E-mail: zzalina@usm.my or zalina240678@yahoo.com 
history of opioid use disorders and/or prescriptions for methadone or other maintenance medications than other patients $(4,5,7)$. Poor pain management can contribute to discontinuation of MMT and the consequent continued use of illicit opiates poses challenges in the treatment of patients with opiate dependence (4).

Patient factors may also contribute to poor pain management in opioid dependent patients. Crosstolerance to opioids may be present $(9,10)$ and patients may need more, not less, analgesia. Indeed, evidence has shown that opioid dependent patients require higher than normal doses of opioid analgesics. Despite significantly greater plasma morphine concentrations, methadone patients experienced minimal antinociception in comparison with controls (10). Although even higher morphine doses may achieve some pain relief, this may be at the cost of unacceptable respiratory depression (9). It is thus important for physicians, pharmacists, nurses and other healthcare professionals to understand pain sensitivity among patients on MMT for more effective pain management in this population (6).

Pain sensitivity has been shown to vary following a circadian pattern (11). Unfortunately, information about how pain sensitivity among patients receiving MMT changes over 24-h dosing interval is currently lacking. Previous studies investigated pain sensitivity among opioid dependent patients at a single point in time (12-14) and examined patients for only a short duration of 2 to $3 \mathrm{~h}(9,15,16)$. An experimental pain study that document responses over a $24 \mathrm{~h}$ period in patient population could minimize the possible diurnal variation in cold pressor pain response.

A single pain induction technique, cold pressor test (CPT), which most discriminating pain sensitivity between MMT patients and healthy opioid naive subjects was used in the current study $(13,15)$. The CPT is a standardized and naturalistic tonic and acute pain model. It produces pain analogous to naturally occurring types of pain. It effectively mimics chronic pain conditions like dental and back pain, allowing for a valid generalization to clinical pain states (17). According to Compton et al. (18) and Doverty et al. (15), the use of other pain induction techniques such as electrical stimulation (ES) may not be the best way to study pain response among MMT patients.
This study investigated pain sensitivity using the CPT in opioid dependent patients on MMT and opioid naive individuals to compare time independent and time-dependent pain tolerance between this MMT patients and the general population at six assessment points over $24 \mathrm{~h}$.

\section{METHODS}

\section{Study design}

This non-interventional study was conducted on two consecutive days for a total duration of at least $24 \mathrm{~h}$. On the first study day, subjects arrived in the morning at 8:00 AM and remained for at least $12 \mathrm{~h}$ for CPT. Subjects went home at the end of the first study day and returned the following day to complete the 24-h CPT cycle. Subjects were discharged after they had completed the last CPT. This study was conducted at the Clinical Trial Unit (CTU), Hospital USM, Kota Bharu, Kelantan from March to October, 2013.

\section{Subject selection and recruitment}

Opioid naive subjects were defined as individuals who have not taken any opioids including morphine and methadone to their best knowledge and were presumed so after two consecutive negative urine screenings for drugs. Opioid naive subjects were recruited from the local community. Opioid dependent patients were diagnosed according to the DSM IV criteria (19). They met the inclusion and exclusion criteria of the national MMT program and were currently on the national MMT program at Hospital Universiti Sains Malaysia and other MMT clinics in Kelantan. All were stabilized in treatment, defined as having been enrolled in the program for more than one month with no change of methadone dosage over the past one month.

Inclusion criteria included: 1) Malay for at least up to three generations, 2) male aged more than 18 $y, 3)$ free of acute medical, surgical and psychiatric illness, 4) free of acute or chronic medical, surgical and psychiatric illness that required concurrent medical, surgical or psychiatric therapy, 5) free of regular use of alcohol, 6) free of intoxication, 7) able to understand study protocols and to follow simple study instructions, and 8) willing to sign written informed consent. We selected only Malay male subjects in this study, trying to minimise the possible ethnic factors $(20,21)$ and gender effects (22-25) on pain parameters and because this reflects our patient population (3). 
Excluded were: 1) Individuals with diabetes mellitus, 2) individuals infected with human immunodeficiency virus (HIV) and were on highly active antiretroviral therapy (HAART), 3) individuals with major psychiatric illness such as schizophrenia, 4) individuals who were currently taking illicit benzodiazepines, cannabinoids and barbiturates, 5) individuals with peripheral vascular disease, 6) individuals on regular anticonvulsants, neuroleptics or analgesics, 7) individuals with chronic or ongoing acute pain, 8) individuals with a history of analgesics ingestion within $3 \mathrm{~d}$ prior to the CPT, and 9) individuals with severe cognitive impairment which might interfere with pain assessments and/or communication.

\section{Data collection and assessment of subjects}

A brief explanation of the study was provided to the enrolled subjects. Urine drug screens were performed twice in the week prior to the CPT. Each subject provided urine samples that were analysed on site for morphine, tetrahydrocannabinol, amphetamines and benzodiazepines using drugs of abuse rapid test, F.A.C.T.S TM 4 in 1 Combo Dipcard Rapid Test (MOR/THC/AMP/BZO) (Scientifacts Sdn. Bhd., Malaysia). Subjects who failed the urine test during the first urine drug screening test were excluded from the study. Subjects who had two consecutive negative urine tests (during the first and second urine drug screening test) proceeded to the Clinical Trial Unit (CTU), Hospital USM for further evaluation.

Opioid dependent subjects had been instructed not to ingest methadone from their MMT clinic on the test morning so that pain sensitivity could be assessed before their morning dose of methadone. Opioid dependent and opioid naive groups were given separate appointment dates for CPT. Of these subjects, all those who passed the first and second urine drug screening tests, proceeded to enrolment into the trial.

Subjects were asked for a history of analgesics consumption within the previous $72 \mathrm{~h}$ prior to testing and for a history of any painful conditions to ensure that they were pain free. Subjects who had been found to have the previously mentioned conditions were classified as a screen failure and not eligible for the study. Subjects who fulfilled all criteria were then interviewed. The selected subjects were interviewed by the researcher using a standard performa. The information recorded included socio-demographic variables. The accuracy of the information given by patients was checked against their medical records; especially regarding doses of the methadone. Subjects who were deemed ineligible were discharged at that point without completing the assessment. Only one interviewer, ZZ, was involved in the interviewing activities.

Cold pressor tests for both opioid dependent and opioid naive subjects took place in a quiet, dedicated area at the CTU. Details of the CPT instruments and procedures are described below.

All opioid dependent patients were administered methadone syrup $(5 \mathrm{mg} / \mathrm{ml})$ at their respective single daily doses and received their methadone dose at usual time on the first day and second day of the study. Study personnel observed all methadone dose administrations.

Subjects were provided with a lounge at the CTU to relax in between CPT assessment. Throughout this study, data were recorded in a standard performa by the investigator.

\section{Cold pressor test (CPT)}

The CPT method utilized in the current study was adapted based on previous reports from Chen et al. (17) and Compton et al. (26). The reliability and validity of the CPT has also been extensively established (17, 27, 28). Indeed, CPT has been previously used extensively worldwide to measure pain sensitivity among opioid dependent patients $(9$, 10, 12-16, 29-31). Many studies of human pain perception have used cold pain model to study drug-free healthy individuals (25).

The CPT apparatus consisted of a 48 quart coolbox filled with a mixture of two-thirds crushed ice and one-third tap water. The resulting ice-water mix was stirred to maintain a constant temperature of $0-2{ }^{\circ} \mathrm{C}$ by adding ice with temperature constantly being monitored by a digital indooroutdoor-thermometer (TFA Dostmann GmbH \& Co.KG, Wertheim).

A standardized written instruction was read out aloud to all the subjects before conducting the first CPT. Subjects were also informed that they could withdraw from the study at anytime. At $0,2,4,8$, 12 and $24 \mathrm{~h}$ post-dose patients were asked to roll up their sleeve and removed watches or jewelry from their non-dominant hand and arm. Subjects were asked to verbally indicate when they could no longer tolerate the stimulus to remove their arm from the container. Subjects were instructed to place their non-dominant hand and forearm in the 
ice bath with palm flat on the bottom of the tank; ice water covered the hand and approximately 10 $\mathrm{cm}$ of the forearm. Subjects were not spoken to during the test to minimize distraction or cues for time. The test was truncated at $300 \mathrm{~s}$, as after this time, numbness set in and pain diminished $(26,32$, 33).

Pain tolerance was recorded as the time elapsed in seconds when the subject withdrew his hand after immersion. Pain tolerance for subjects that did not withdraw their hand for the entire $300 \mathrm{~s}$ was recorded as $300 \mathrm{~s}$. After withdrawal of the immersed hand, each subject was given a piece of dry towel to dry their hand. Subjects were asked to report to the investigator if the pain was felt for more than $30 \mathrm{~min}$.

For opioid dependent subjects, the first test was performed approximately $30 \mathrm{~min}$ before their morning dose of methadone $(0 \mathrm{~h})$, and at 2, 4, 8, 12, and $24 \mathrm{~h}$ after the dose. Opioid naive subjects did so without taking methadone and, hence, the mentioned time intervals. We examined cold pressor responses six times over a $24 \mathrm{~h}$ period, in order to minimize the possible diurnal variation in cold pressor pain response (11). The test was administered by one trained research assistant (SHH).

\section{STATISTICAL ANALYSIS}

Mean and standard deviation (SD) were computed for numerical variables. The difference of mean pain tolerance within opioid naive and MMT group based on time were analysed using one-way within subjects repeated measures ANOVA (RMANOVA). The mean difference of pain tolerance between opioid naive and MMT groups were analysed using RM-ANOVA between group analyses regardless of time and also with regard to time. If the time factor is statistically significant in the ANOVA test, then Bonferroni pairwise comparisons were computed to identify specific differences between time periods. The statistical analysis was carried out using SPSS/Win software (Version 11.0, SPSS, Inc., Chicago, IL). The limit of significance was set at 0.05 .

\section{ETHICS}

The protocols for the study were approved by the Human Research Ethics Committee (HREC), Universiti Sains Malaysia (USM) in Kelantan,
Malaysia (Reference number: USMKK/PPP/JEPeM (253.3 [14]). Ethical approval was also obtained from the Medical Research \& Ethics Committee (MREC) at the Ministry of Health (MOH), Malaysia (Reference number: NMRR-13-52416614). Confidentiality of the subjects was strictly maintained and subjects were free to withdraw at any time.

\section{RESULTS}

\section{Study participants}

From March until October 2013, a total of 152 opioid naive subjects and 148 opioid dependent patients fulfilled inclusion and exclusion criteria, gave informed consent and completed the study. Of the 169 potential opioid dependent patients who were invited to participate, a total of 21 subjects were excluded. One patient did not participate in the study due to a lack of interest. Twelve patients were excluded for health reasons, three for scheduling conflicts and six for miscellaneous reasons. Of the 184 control subjects who were invited to participate, 32 failed screening; four for health reasons, 24 for scheduling conflicts and four for miscellaneous reasons.

Among opioid naive subjects, age averaged 27.46 (SD 10.10) y with a range between 18 to 63 y. Their mean body mass index (BMI) was 24.76 (SD 5.37) and ranged from 15.0 to $45.0 \mathrm{~kg} / \mathrm{m}^{2}$. Among opioid dependent subjects, their age averaged 36.86 (SD 6.13) y and ranged from 25 to 55 years old. Their mean BMI was 22.17 (SD 3.57) and it ranged from 14.9 to $36.3 \mathrm{~kg} / \mathrm{m}^{2}$. The majority of the patients used more than one illicit drug in their lifetime with marijuana and amphetamines being most widely used. Just ten $(6.8 \%)$ patients reported using only morphine and related substances as past illicit drug use. Their mean age of first time illicit drug use was 19.23 (SD 4.20) y, and ranged from 12 to $33 \mathrm{y}$. Their mean current daily dosage of methadone was 72.70 (SD 28.25) $\mathrm{mg}$, and it ranged from 20 to $160 \mathrm{mg}$.

\section{Pain response among opioid dependent patients and opioid naive subjects}

Repeated measures ANOVA within subjects analysis showed a significant difference in pain tolerance among opioid dependent patients based on time $(p<0.001)$. Significant differences in pain tolerance were observed only between $0 \mathrm{~h}-24 \mathrm{~h}(p$ $<0.001), 2 \mathrm{~h}-24 \mathrm{~h}(p=0.004), 4 \mathrm{~h}-24 \mathrm{~h}(p<$ 
$0.001)$ and $12 \mathrm{~h}-24 \mathrm{~h}(p<0.001)$. Repeated measures ANOVA within subjects analysis showed no significant difference in pain tolerance among opioid naive subjects based on time at $0,2,4,8,12$ and $24 \mathrm{~h}(p=0.177)$.

\section{Comparison of pain response between opioid dependent patients and opioid naive subjects}

Table 1 shows the overall mean difference of pain tolerance between opioid naive subjects compared to MMT patients analysed using time independent RM-ANOVA between group analyses. The adjusted mean pain tolerance to the CPT among the patients of 34.17 s $(95 \%$ CI $24.86,43.49)$ was significantly shorter compared to opioid naive subjects, $61.36 \mathrm{~s}$ $(52.23,70.48)(p<0.001)$.

Time-dependent mean pain tolerance was also significantly different when opioid naive subjects were compared to opioid dependent patients $(p=$ 0.016). Table 2 shows mean pain tolerance of the opioid naive subjects and opioid dependent patients at six different measurement times over $24 \mathrm{~h}$. Opioid dependent patients had significantly shorter pain tolerance at all six different measurement times compared to opioid naive subjects.

Figure 1 shows the mean pain tolerance for both opioid naive subjects and opioid dependent patients at all six different measurement times. At the time of estimated trough concentration or prior to next dosing (i.e. at $0 \mathrm{~h}$ and $24 \mathrm{~h}$ ), the mean difference of pain tolerance between opioid naive subjects compared to MMT patients was larger than that at the time of estimated peak concentration (i.e. at $2 \mathrm{~h}$ and $4 \mathrm{~h}$ ).

\section{DISCUSSION}

Our findings that Malay opioid dependent patients exhibited shorter cold pressor pain tolerances compared to the controls are consistent with results of previous studies, which is a clear sign of higher sensitivity to pain or hyperalgesia. Previously, Compton et al. (30) evaluated pain tolerance among opioid addicts stabilized on MMT in the United States comprising African-Americans, Latinos, Whites and other ethnicities. They compared pain tolerance to CPT in methadone maintained addicts ( 37 males and 23 females; mean age, 40.6 y) with control subjects (37 males and 23 females; mean age, $34.3 \mathrm{y})$. They also found that pain tolerance time among the 60 patients on MMT, were significantly lower than in 60 controls $(p=0.002)$. They concluded that their methadone maintained addicts were more sensitive to cold pressor pain compared to control subjects.

In another study Pud et al. (14), examined 60 heroin or methadone addicts (50 males and 10 females; mean age, $33.1 \mathrm{y}$; range, 19 - 59) attending a 4-week inpatient detoxification program. They also examined 70 healthy volunteers (38 males and 32 females; mean age, $24.3 \mathrm{y}$; range, $18-40$ y) from Haifa, Israel as controls. They wanted to test if drug addicts, while actively consuming opioids, differ from normal subjects in their pain perception in response to the CPT. They reported that their opioid addicts exhibited significantly shorter time required for hand withdrawal compared to controls $(p=0.001)$.

Another interesting finding of our study is the significant difference in the cold pressor pain tolerance between the opioid dependent patients and opioid naive subjects were found at all six CPT assessment points when analysed based on time ( $p$ $=0.016$ ). Malay opioid dependent patients were evidently hyperalgesic (low pain tolerance) throughout $24 \mathrm{~h}$. A previous South Australia study involving 16 methadone maintained patients and 16 age- and sex-matched control subjects determined the differences in nociceptive responses at trough and peak plasma methadone concentrations (15). It was found that, methadone maintained patients were also substantially less pain tolerant than

Table 1. Overall mean difference of pain tolerance between opioid naive subjects and opioid dependent patients measured at $0,2,4,8,12$ and $24 \mathrm{~h}$

\begin{tabular}{llll}
\hline Pain tolerance $(\mathrm{s})$ & Mean $(95 \% \mathrm{CI})$ & Mean difference $(95 \% \mathrm{CI})$ & $F_{\text {stat. }(\mathrm{df}){ }^{\mathrm{a}}} p^{\text {v value* }}$ \\
\hline Opioid naive & $61.36(52.23,70.48)$ & $27.18(14.14,40.23)$ & $16.83(1)$ \\
Opioid dependent & $34.17(24.86,43.49)$ & & $<\mathbf{0 . 0 0 1}$ \\
\hline $\begin{array}{l}{ }^{\mathrm{a}} \text { Repeated measured ANOVA between group analysis was applied. } \\
{ }^{p} \text { value is significant at }<0.05\end{array}$ & & \\
CI, confidence interval & & \\
\hline
\end{tabular}


Table 2. Comparison of pain tolerance between opioid naive subjects and opioid dependent patients based on time at six different measurement times over $24 \mathrm{~h}$

\begin{tabular}{|c|c|c|c|}
\hline \multirow[t]{2}{*}{ Pain tolerance (s) } & \multirow[t]{2}{*}{ Mean } & \multicolumn{2}{|l|}{$95 \% \mathrm{CI}$} \\
\hline & & Lower limit & Upper limit \\
\hline \multicolumn{4}{|l|}{ At $0 \mathrm{~h}$} \\
\hline Opioid naive & 66.39 & 56.66 & 76.12 \\
\hline Opioid dependent & 35.18 & 25.25 & 45.11 \\
\hline Mean difference & 31.21 & & \\
\hline \multicolumn{4}{|l|}{ At $2^{\text {nd }} h$} \\
\hline Opioid naive & 62.98 & 52.21 & 73.75 \\
\hline Opioid dependent & 35.39 & 24.40 & 46.37 \\
\hline Mean difference & 27.59 & & \\
\hline \multicolumn{4}{|l|}{ At $4^{\text {th }} \mathrm{h}$} \\
\hline Opioid naive & 60.23 & 50.04 & 70.41 \\
\hline Opioid dependent & 36.44 & 26.05 & 46.83 \\
\hline Mean difference & 23.79 & & \\
\hline \multicolumn{4}{|l|}{ At $8^{\text {th }} \mathrm{h}$} \\
\hline Opioid naive & 56.49 & 46.55 & 66.43 \\
\hline Opioid dependent & 34.30 & 24.15 & 44.44 \\
\hline Mean difference & 22.19 & & \\
\hline \multicolumn{4}{|l|}{ At $12^{\text {th }} \mathrm{h}$} \\
\hline Opioid naive & 59.41 & 48.83 & 69.99 \\
\hline Opioid dependent & 36.46 & 25.67 & 47.26 \\
\hline Mean difference & 22.95 & & \\
\hline \multicolumn{4}{|l|}{ At $24^{\text {th }} \mathrm{h}$} \\
\hline Opioid naive & 62.64 & 52.57 & 72.72 \\
\hline Opioid dependent & 27.26 & 16.98 & 37.54 \\
\hline Mean difference & 35.38 & & \\
\hline
\end{tabular}

controls at both $0(p \leq 0.0001)$ and $3 \mathrm{~h}(p \leq 0.0001)$, strengthening our findings.

Compton et al. (16) have also recently studied the experimental (cold pressor and electrical stimulation) pain responses among drug free control $(\mathrm{n}=21)$ for comparison with that among 82 heroindependent subjects randomized to methadone $(\mathrm{n}=$ $11)$ or buprenorphine $(n=64)$. They reported that baseline (treatment entry) pain tolerance with the CPT in heroin-dependent subjects was significantly shorter than in controls when measured just prior to dosing $(p=0.015)$. Again, at peak levels $(3 \mathrm{~h}$ after dosing), significant difference was evident between the groups in terms of pain tolerance $(p=0.003)$ suggesting hyperalgesia was present.

Taken together, the finding of shorter cold pressor pain tolerance times (withdrawal latencies) in opioid maintained addicts compared to healthy controls is quite consistent across multiple studies involving various race and ethnicity in California, USA (16, 30), in Israel (14) and in Australia (15). Notably, the pain sensitivity data in our population was in line with other studies previously published in other ethnic groups providing further evidence that opioid dependent participants are more sensitive to painful stimuli than are controls. 


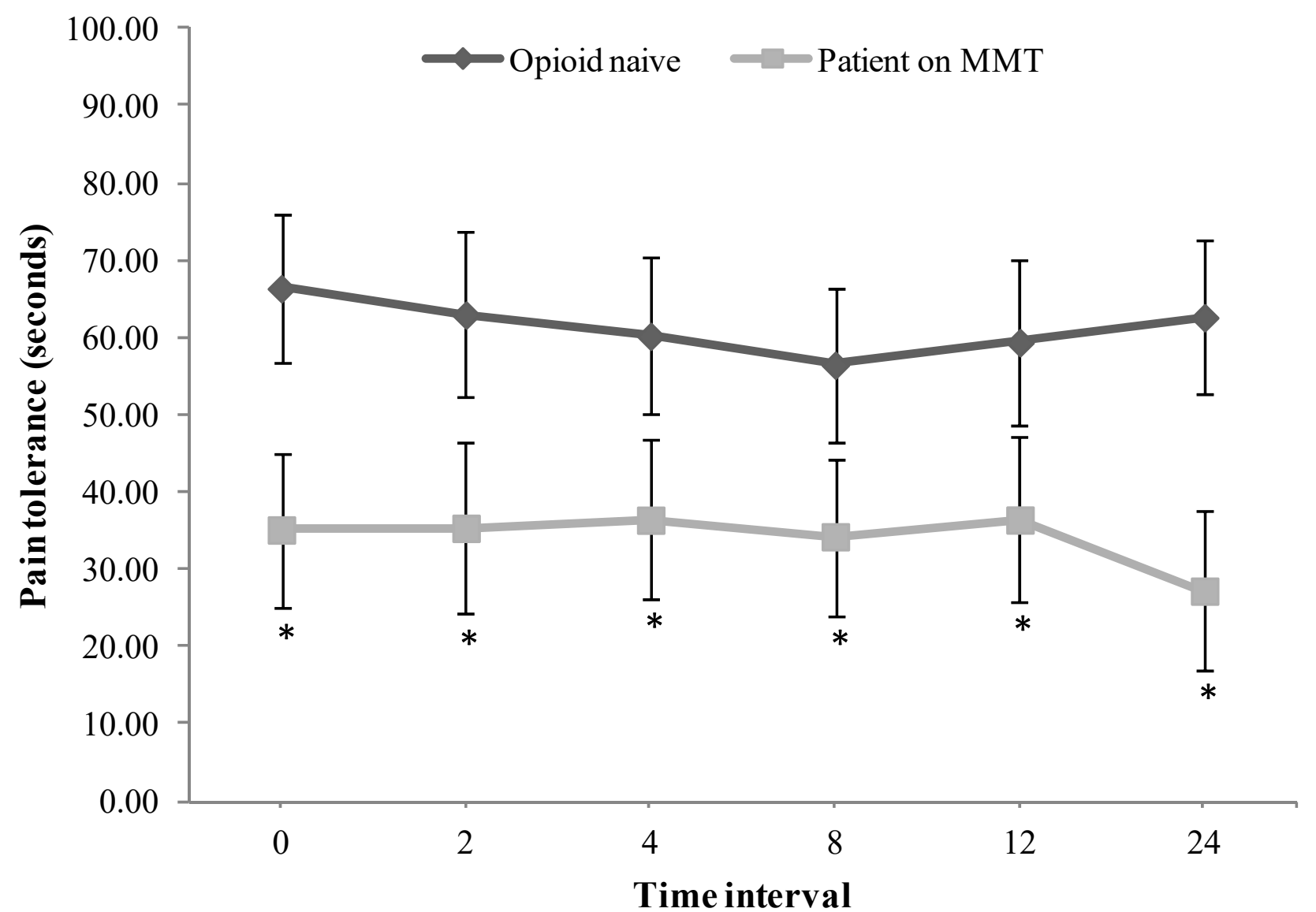

Figure 1. Profile plot of mean ( $\pm 95 \%$ confidence interval) pain tolerance at $0,2,4,8,12$ and $24 \mathrm{~h}$ for both opioid naive subjects and opioid dependent patients. Independent $t$-test analyses revealed that the pain tolerances were markedly lower in opioid dependent patients as compared to opioid naive subjects at $0,2,4,8,12$ and $24 \mathrm{~h}$. Repeated measure ANOVA between group analysis also showed that time-dependent mean pain tolerance was significantly different when opioid naive subjects were compared to opioid dependent patients $(p=0.016) .{ }^{*} p<0.005$ compared to the corresponding data of opioid naive subjects; MMT, methadone maintenance therapy.

These findings may indicate that opioid dependent patients on MMT are a relatively pain-intolerant group of individuals.

The strength of our current study is that opioid naive individuals and opioid dependent patients on MMT were exposed to six CPT measurements during $24 \mathrm{~h}$. Results showed that our Malay opioid dependent patients receiving MMT were evidently hyperalgesic (low pain tolerance) over 24-h dosing interval. Therefore, the results of our study have not only added to the growing evidence of opioid induced hyperalgesia with opioid dependent patients on MMT but have provided a more thorough spectrum of pain study over $24 \mathrm{~h}$ using larger number of samples as opposed to previous studies of 2 to $3 \mathrm{~h}$ which only involved 16 to 82 patients $(9,15,16)$.
In addition, the mean difference of pain tolerance between opioid naive subjects compared to MMT patients at the time of estimated trough concentration or prior to next dosing (i.e. at $0 \mathrm{~h}$ and $24 \mathrm{~h}$ ) was larger than that at the time of estimated peak concentration (i.e. at $2 \mathrm{~h}$ and $4 \mathrm{~h}$ ). These findings have therapeutic implications. First, this study provide clinical research evidence of the presence of more hyperalgesia at the time of estimated trough concentration or prior to next dosing of methadone. It is possible that the good pain relief is more difficult to be achieved among opioid dependent patients receiving MMT at this point of time. Second, as the goal of acute and chronic pain management is to achieve adequate pain control, the clinician may use this important information in making decision about multimodal 
analgesia and/or adjuvants to be prescribed, and may justify prescription of additional analgesia at this point of time, as required in addition to baseline analgesic dosage.

The importance of our current study is that this study can potentially have a large audience. A conservative estimate puts the number of people using illicit drugs in Malaysia at 1000 000. More than half of them use illicit opiates and a further 50 to 100000 of them are treated with MMT. Although pain management in this group of people has not attracted much attention, probably the result of stigma and discrimination, its importance cannot ethically be underestimated. This study could serve as a starting point from which further studies could be performed to better detail the pain experience.

Compton et al. (30) have suggested that there may be a genetic explanation for the noted hyperalgesia among individuals with opioid dependence, a possibility supported by animal and human studies of genetic polymorphisms such as opioid receptor, mu-1 gene (OPRM1) $(34,35)$. Individuals with genetic polymorphism might be at risk of both hyperalgesia and opioid dependence (36). However, there are several lines of evidence suggesting that hyperalgesia in opioid dependent patients actively using opioid maintenance therapy is a result of long-term opioid administration, or a so-called opioid induced hyperalgesia $(36,37)$, a possibility that is supported by: 1) Hay et al. (12), who found that patients with chronic pain managed with opioids and methadone-maintained subjects are hyperalgesic compared to opioid naive subjects; 2) Compton et al. (16), who found that heroindependent participants are hyperalgesic, and subsequent maintenance on methadone or buprenorphine does not appear to appreciably improve over the course of treatment; and 3) by Gardell et al. (38), who found that prolonged activation of the $\mu$-opioid receptor by $\mu$-opioid agonist, up-regulated spinal dynorphin and ultimately produced thermal and tactile hypersensitivity and antinociceptive tolerance.

Regardless of the reasons for development of hyperalgesia, healthcare professionals should learn that MMT subjects are more pain sensitive or hyperalgesic. Most recently, Bounes et al. (39) did a survey to analyze the current practices on acute pain management of patients under opioid maintenance treatment (OMT). Their results showed that only $40 \%$ of physicians estimated that patients under OMT (buprenorphine or methadone) feel more pain than other patients, $10 \%$ estimated that they feel less pain, and $53 \%$ estimated that the patients felt the same amount of pain. These data demonstrate the misconceptions of physicians on the pain tolerance of opioid maintained patients. Therefore, our current study provide data indicating that hyperalgesia among opioid dependent patients receiving MMT can actually occur in clinical practice, which may be useful in convincing the health care providers that the methadone maintained patients who seek for analgesic therapy is truely experiencing pain or having hyperalgesia.

Pain in this population of patients should be assessed, monitored and evaluated seriously and treatment of pain should be done aggressively. Physicians, pharmacists, nurses and other healthcare professionals should also encourage patients to communicate their pain, counsel patients concerning feelings associated with pain and implement teaching program to both patients and family members that addresses prescribed pain treatment to improve MMT patients' pain problems and overall treatment outcomes.

In this study, several factors influencing pain perception were controlled included ethnicity and gender. On the other hand, several other factors were not controlled (e.g. age and BMI). Thus, opioid naive subjects were significantly younger than opioid dependent subjects and they further differred significantly in BMI. There is no suitable information in the literature on whether an age and BMI differences of $9.4 \mathrm{y}$ and $2.59 \mathrm{~kg} / \mathrm{m}^{2}$, respectively could affect the results of pain sensitivity. Furthermore, our post hoc tests indicated no correlation between age and pain responses in both opioid naive $(r=-0.132, p=$ $0.106)$ and opioid dependent group $(r=-0.028, p=$ 0.738). As well, there were no correlation between BMI and pain responses in both opioid naive $(r=$ $0.055, p=0.504)$ and opioid dependent group $(r=$ $0.101, p=0.223$ ).

\section{CONCLUSIONS}

A study was successfully executed an evaluation of pain sensitivity among opioid dependent patients and opioid naive individuals. Most similar studies were done at a single point in time. The current study however also evaluated pain sensitivity at six post-dose points over $24 \mathrm{~h}$. These patients feel more pain throughout the day. Analgesia for an opiateusing population should be individualized and 
tailored to meet the needs of an opiate-using population.

\section{ACKNOWLEDGEMENTS}

We wish to thank Prof. Howard McNulty of the Institute of Pharmacy and Bio-medical Sciences University of Strathclyde Glasgow UK for English language editing and proof reading of this article. We are grateful to Nur Amalina Che Rahim and Wan Izzati Mariah Binti Wan Hassan from Department of Pharmacy, Hospital Universiti Sains Malaysia, Kubang Kerian, Kelantan, Malaysia; Hazwan Bin Mat Din and Wan Nor Arifin Wan Harun, Biostatistics \& Research Methodology Unit, School of Medical Sciences, Universiti Sains Malaysia; and all the members of Pharmacogenetics and Novel Therapeutics Cluster, Institute for Research in Molecular Medicine (INFORMM), Universiti Sains Malaysia (USM) for their support and valuable suggestions during the study.

\section{REFERENCES}

1. Amato L, Minozzi S, Davoli M, Vecchi S. Psychosocial combined with agonist maintenance treatments versus agonist maintenance treatments alone for treatment of opioid dependence. Cochrane Database Syst Rev, 2011:CD004147.

2. Dunn KE, Brooner RK, Clark MR. Severity and interference of chronic pain in methadonemaintained outpatients. Pain Med, 2014;15:15401548.

3. Manan MM, Ali SM, Khan MA, Jafarian S, Hameed MA. Review on the demographic and social impact of methadone-medication therapy on Malaysian patients. Pak J Pharm Sci, 2013;26:841-846.

4. Eyler EC. Chronic and acute pain and pain management for patients in methadone maintenance treatment. Am J Addict, 2013;22:7583.

5. Alford DP, Compton P, Samet JH. Acute pain management for patients receiving maintenance methadone or buprenorphine therapy. Ann Intern Med, 2006;144:127-134.

6. Savage SR, Kirsh KL, Passik SD. Challenges in Using Opioids to Treat Pain in Persons With Substance Use Disorders. Addict Sci Clin Pract 2008:4:4-25.

7. Scimeca MM, Savage SR, Portenoy R, Lowinson J. Treatment of pain in methadone-maintained patients. Mt Sinai J Med, 2000;67:412-422.

8. Hines S, Theodorou S, Williamson A, Fong D, Curry K. Management of acute pain in methadone maintenance therapy in-patients. Drug Alcohol Rev, 2008;27:519-523.

9. Athanasos P, Smith CS, White JM, Somogyi AA, Bochner F, Ling W. Methadone maintenance patients are cross-tolerant to the antinociceptive effects of very high plasma morphine concentrations. Pain, 2006;120:267-275.

10. Doverty M, Somogyi AA, White JM, Bochner F, Beare $\mathrm{CH}$, Menelaou A, Ling W. Methadone maintenance patients are cross-tolerant to the antinociceptive effects of morphine. Pain, 2001;93:155-163.

11. Glynn CJ, Lloyd JW. The diurnal variation in perception of pain. Proc R Soc Med, 1976;69:369372.

12. Hay JL, White JM, Bochner F, Somogyi AA, Semple TJ, Rounsefell B. Hyperalgesia in opioidmanaged chronic pain and opioid-dependent patients. J Pain, 2009;10:316-322.

13. Krishnan S, Salter A, Sullivan T, Gentgall M, White J, Rolan P. Comparison of pain models to detect opioid-induced hyperalgesia. J Pain Res, 2012;5:99-106.

14. Pud D, Cohen D, Lawental E, Eisenberg E. Opioids and abnormal pain perception: New evidence from a study of chronic opioid addicts and healthy subjects. Drug Alcohol Depend, 2006;82:218-223.

15. Doverty M, White JM, Somogyi AA, Bochner F, Ali R, Ling $\mathrm{W}$. Hyperalgesic responses in methadone maintenance patients. Pain, 2001;90:91-96.

16. Compton P, Canamar CP, Hillhouse M, Ling W. Hyperalgesia in heroin dependent patients and the effects of opioid substitution therapy. J Pain, 2012;13:401-409.

17. Chen AC, Dworkin SF, Haug J, Gehrig J. Human pain responsivity in a tonic pain model: psychological determinants. Pain, 1989;37:143160.

18. Compton $\mathrm{P}$, Geschwind $\mathrm{DH}$, Alarcon $\mathrm{M}$. Association between human mu-opioid receptor gene polymorphism, pain tolerance, and opioid addiction. Am J Med Genet B Neuropsychiatr Genet, 2003;121B:76-82.

19. American Psychiatric Association. Diagnostic and statistical manual of mental disorders, Fourth Edition: American Psychiatric Association, Washington, DC; 1994.

20. Shavers VL, Bakos A, Sheppard VB. Race, ethnicity, and pain among the U.S. adult population. J Health Care Poor Underserved, 2010;21:177-220.

21. Edwards CL, Fillingim RB, Keefe F. Race, ethnicity and pain. Pain, 2001;94:133-137. 
22. Fillingim RB, Maixner W. Gender differences in the responses to noxious stimuli. Pain Forum, 1995;4:209-221.

23. Alabas OA, Tashani OA, Tabasam G, Johnson MI. Gender role affects experimental pain responses: a systematic review with meta-analysis. Eur J Pain, 2012;16:1211-1223.

24. Fillingim RB, King CD, Ribeiro-Dasilva MC, Rahim-Williams B, Riley JL, 3rd. Sex, gender, and pain: a review of recent clinical and experimental findings. J Pain, 2009;10:447-485.

25. Racine M, Tousignant-Laflamme Y, Kloda LA, Dion D, Dupuis G, Choiniere M. A systematic literature review of 10 years of research on sex/gender and experimental pain perception - part 1: are there really differences between women and men? Pain, 2012;153:602-618.

26. Compton P, Charuvastra VC, Ling W. Pain intolerance in opioid-maintained former opiate addicts: effect of long-acting maintenance agent. Drug Alcohol Depend, 2001;63:139-146.

27. Lewis GN, Heales L, Rice DA, Rome K, McNair PJ. Reliability of the conditioned pain modulation paradigm to assess endogenous inhibitory pain pathways. Pain Res Manag, 2012;17:98-102.

28. Ruscheweyh R, Stumpenhorst F, Knecht S, Marziniak M. Comparison of the cold pressor test and contact thermode-delivered cold stimuli for the assessment of cold pain sensitivity. J Pain, 2010;11:728-736.

29. Peles E, Schreiber S, Hetzroni T, Adelson M, Defrin R. The differential effect of methadone dose and of chronic pain on pain perception of former heroin addicts receiving methadone maintenance treatment. J Pain, 2011;12:41-50.

30. Compton P, Charuvastra VC, Kintaudi K, Ling W. Pain responses in methadone-maintained opioid abusers. J Pain Symptom Manage, 2000;20:237245 .
31. Compton MA. Cold-pressor pain tolerance in opiate and cocaine abusers: correlates of drug type and use status. J Pain Symptom Manage, 1994;9:462-473.

32. Wolf S, Hardy JD. Studies on pain. Observations on pain due to local cooling and on factors involved in the "cold pressor" effect. J Clin Invest 1941;20:521-533.

33. Harris G, Rollman GB. The validity of experimental pain measures. Pain, 1983;17:369376.

34. Bond C, LaForge KS, Tian M, Melia D, Zhang S, Borg L, Gong J, Schluger J, Strong JA, Leal SM, Tischfield JA, Kreek MJ, Yu L. Single-nucleotide polymorphism in the human mu opioid receptor gene alters $\beta$-endorphin binding and activity: Possible implications for opiate addiction. Proc Natl Acad Sci U S A 1998;95:9608-9613.

35. Mogil JS, Sternberg WF, Marek P, Sadowski B, Belknap JK, Liebeskind JC. The genetics of pain and pain inhibition. Proc Natl Acad Sci U S A 1996;93:3048-3055.

36. White JM. Pleasure into pain: the consequences of long-term opioid use. Addict Behav, 2004;29:1311-1324.

37. Lee M, Silverman SM, Hansen H, Patel VB, Manchikanti L. A comprehensive review of opioid-induced hyperalgesia. Pain Physician, 2011;14:145-161.

38. Gardell LR, King T, Ossipov MH, Rice KC, Lai J, Vanderah TW, Porreca F. Opioid receptormediated hyperalgesia and antinociceptive tolerance induced by sustained opiate delivery. Neurosci Lett 2006;396:44-49.

39. Bounes V, Jouanjus E, Roussin A, LapeyreMestre M. Acute pain management for patients under opioid maintenance treatment: what physicians do in emergency departments? Eur J Emerg Med, 2014;21:73-76. 